\title{
Communication
}

\section{Surface Reconstruction on Electro-Spun PVA/PVP Nanofibers by Water Evaporation}

\author{
Feipeng Wang ${ }^{1, *(\mathbb{D})}$, Zheng Zhang ${ }^{1}{ }^{(\mathbb{C}}$, Yuyang Yan ${ }^{1}$, Zijia Shen ${ }^{1}$, Qiang Wang ${ }^{1}$ and Reimund Gerhard ${ }^{2}(\mathbb{D})$ \\ 1 State Key Lab of Power Transmission Equipment \& System Security and New Technology, \\ Chongqing University, Chongqing 400044, China; 201911021006@cqu.edu.cn (Z.Z.); \\ 20143232@cqu.edu.cn (Y.Y.); shenza@mail.uc.edu (Z.S.); wangqiang0609@cqu.edu.cn (Q.W.) \\ 2 Institute of Physics and Astronomy, Faculty of Science, University of Potsdam, \\ 14476 Potsdam-Golm, Germany; reimund.gerhard@uni-potsdam.de \\ * Correspondence: fpwang@cqu.edu.cn
}

check for updates

Citation: Wang, F.; Zhang, Z.; Yan, Y.; Shen, Z.; Wang, Q.; Gerhard, R.

Surface Reconstruction on

Electro-Spun PVA/PVP Nanofibers by Water Evaporation. Nanomaterials 2022, 12, 797. https://doi.org/ 10.3390/nano12050797

Academic Editor: Filippo Giannazzo

Received: 13 January 2022

Accepted: 7 February 2022

Published: 26 February 2022

Publisher's Note: MDPI stays neutral with regard to jurisdictional claims in published maps and institutional affiliations.

Copyright: () 2022 by the authors Licensee MDPI, Basel, Switzerland. This article is an open access article distributed under the terms and conditions of the Creative Commons Attribution (CC BY) license (https:// creativecommons.org/licenses/by/ $4.0 /)$.

\begin{abstract}
Tailoring the secondary surface morphology of electro-spun nanofibers has been highly desired, as such delicate structures equip nanofibers with distinct functions. Here, we report a simple strategy to directly reconstruct the surface of polyvinyl alcohol/polyvinylpyrrolidone (PVA/PVP) nanofibers by water evaporation. The roughness and diameter of the nanofibers depend on the temperature during vacuum drying. Surface changes of the nanofibers from smooth to rough were observed at $55^{\circ} \mathrm{C}$, with a significant drop in nanofiber diameter. We attribute the formation of the secondary surface morphology to the intermolecular forces in the water vapor, including capillary and the compression forces, on the basis of the results from the Fourier-transform infrared (FTIR) and $\mathrm{X}$-ray photoelectron (XPS) spectroscopy. The strategy is universally effective for various electro-spun polymer nanofibers, thus opening up avenues toward more detailed and sophisticated structure design and implementation for nanofibers.
\end{abstract}

Keywords: surface reconstruction; intermolecular force; surface-roughened nanofiber

\section{Introduction}

The applications of nanofibers in air and water filtration [1], for catalyzing substrates [2], in various sensors [3], as biomedical scaffolds [4,5] and drug carriers [6] are rapidly increasing, thanks to their much larger surface area. It is well recognized that distinctive secondary morphologies or structures, as found in, e.g., core-shell nanofibers [7], hollow nanofibers [8], triaxial nanofibers [9], tree-like nanofibers [10], surface-roughened nanofibers, etc., can significantly enhance functionality and efficiency. Surface-roughened or grooved nanofibers with an easy-to-prepare secondary morphology are receiving fast increasing attention, as they offer useful interactions with surrounding objects at a low cost. Consequently, they are being implemented at a fast pace into highly cell-attachable scaffolds [11], optimized ethylene-glycol gas sensors [12], stronger bonded construction materials [13], etc. Several routes, such as chemical corrosion or selective dissolution, are feasible for obtaining rough or grooved nanofiber surfaces. Due to their high biocompatibility, polyvinyl alcohol (PVA) nanofibers are very suitable as a polymer matrix for cell-attachable scaffolds. However, it is challenging to achieve sufficiently high roughness on PVA-nanofiber surfaces in order to anchor cells, gas molecules, or cement-hydration products because of the rather low surface tension of PVA solutions, which usually forces the formation of very smooth nanofiber surfaces during electrospinning. Low surface tension and high water-vapor permeability are found to be responsible for preventing the formation of stable secondary structures through surface reconstruction [14,15]. It has been shown that parameters such as solution concentration, externally applied voltage, flow rate, collecting distance, etc., during electrospinning are not suitable for preparing PVA 
fibers with the required secondary morphologies [16]. Consequently, there is a strong motivation to develop well-controlled and efficient methods to achieve high levels of surface reconstruction on PVA nanofibers.

In this work, we report secondary-morphology formation on PVA nanofibers, which was achieved via surface reconstruction of electrospun PVA/polyvinylpyrrolidone (PVP) nanofibers by means of water evaporation in a vacuum. The process was enhanced by selective dissolution as the last step.

\section{Materials and Methods}

The PVA powder, specified as \#1799 $(\mathrm{Mw}=74,885)$ from Aladdin Co. Ltd., Shanghai, China, was selected because it is soluble in hot water (typically at temperatures above $95^{\circ} \mathrm{C}$ ), but not dissolvable in water at RT (room temperature, RT $25^{\circ} \mathrm{C}$ ), and slightly dissolvable in warm water (e.g., at $55^{\circ} \mathrm{C}$ ). The PVP powder, specified as \#K30 (Mw $\left.=44,000 \sim 54,000\right)$ from Chron Co. Ltd., Chengdu, China, was employed as the second polymer because of its significant solubility in both water and ethanol-regardless of temperature. Both polymer powders have purities better than $99 \%$. First, $3 \mathrm{~g}$ PVA and $3 \mathrm{~g}$ PVP were mixed and dissolved in $34 \mathrm{~g}$ of ultra-pure water with a resistivity higher than $1.8 \mathrm{G} \Omega \cdot \mathrm{m}$ at $25^{\circ} \mathrm{C}$. Electro-spinning of the PVA/PVP nanofibers was carried out at a nozzle voltage of $+19 \mathrm{kV}$ and a collector voltage of $-5 \mathrm{Kv}$ (cf. Figure 1) on the electrospinning machine (WL-2, Aibo Zhiye Ion Technology Limited Company, Beijing, China). The flow rate of $0.5 \mathrm{~mL} / \mathrm{h}$ and the distance of $24 \mathrm{~cm}$ between nozzle and collector were controlled by means of a syringe pump and a 3D controller. Nanofibers used immediately after electro-spinning were labeled as $\mathrm{V}$ samples and needed further processing due to their softness and sticky surface. Therefore, the $\mathrm{V}$ samples were subjected to $4 \mathrm{~h}$ vacuum drying either at RT (labeled as VRT) or at 55 (V55), 75 (V75), or $95{ }^{\circ} \mathrm{C}$ (V95) at vacuum drying chamber (DZF-6050, CIMO Medical Instruments Co., Shanghai, China). In order to obtain PVA nanofibers, the four types of samples were immediately treated in $500 \mathrm{~mL}$ ethanol for $48 \mathrm{~h}$ with magnetic stirring at $200 \mathrm{rad} / \mathrm{min}$ to remove PVP by means of selective dissolution, and ethanol residues were removed via RT drying at $100 \mathrm{~Pa}$. The samples that had been selectively dissolved were labeled as VRT-SD, V55-SD, V75-SD, and V95-SD. The followed Scanning Electron Microscopy (SEM; Quattro S, Thermo Fisher Scientific, Waltham, MA, USA) and Energy-Dispersive $X$-ray observations were carried out with a high degree of vacuum $\left(1 \times 10^{-3} \mathrm{~Pa}\right)$ at $25^{\circ} \mathrm{C}$. The XPS (ESCALAB250Xi, Thermo Fisher Scientific, Waltham, MA, USA) test was carried out at $5 \times 10^{-8} \mathrm{~Pa}$ and $25^{\circ} \mathrm{C}$. The FTIR (Alpha, Bruker, Germany) test was carried out at $25^{\circ} \mathrm{C}$.

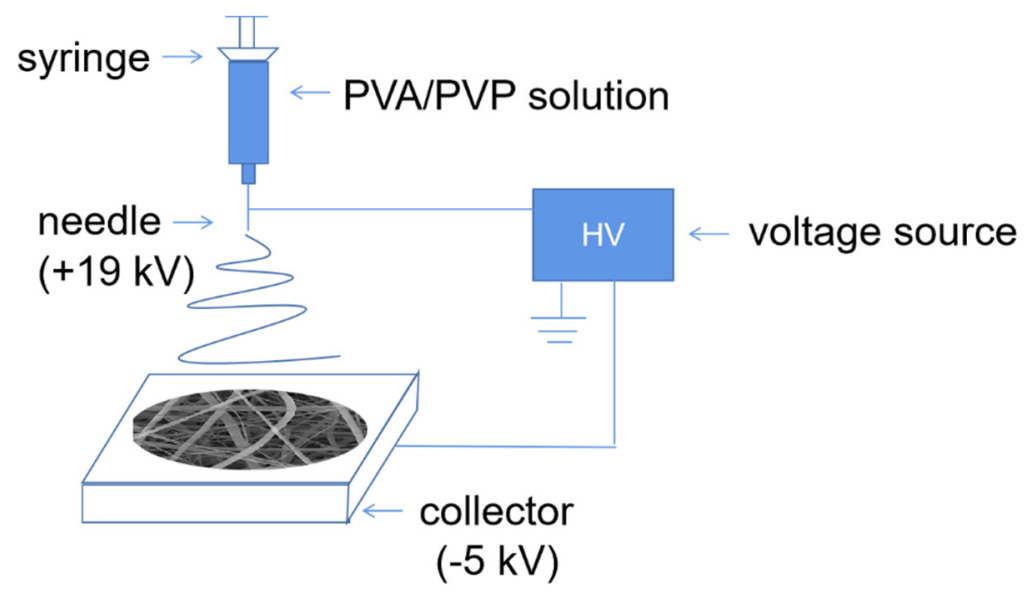

Figure 1. Setup of the experimental electrospinning apparatus.

\section{Results}

The samples in Figure 2 show the nanofiber morphologies, as seen in SEM. Sample V is quite uniform and smooth, and there are no observable pores or stratifications (Figure 2a). 
Vacuum drying at $\mathrm{RT}, 55^{\circ} \mathrm{C}, 75^{\circ} \mathrm{C}$, or $95^{\circ} \mathrm{C}$ brought no observable change to the surface morphology, as seen via SEM (figures not shown). However, after selective dissolution of PVP, all nanofiber samples (VRT-SD, V55-SD, V75-SD, and V95-SD) exhibited significantly different surface morphologies. Sample VRT-SD showed a quite noticeable roughness of $\sim 64 \mathrm{~nm}$ and a remarkably reduced fiber diameter (from 844 to $453 \mathrm{~nm}$, cf. Figure 2a,b). Sample V55-SD exhibited rough fiber surfaces with obvious grooves and depressions. The roughness was estimated as $164 \mathrm{~nm}$, and the fiber diameter was found to only be reduced from 844 to $646 \mathrm{~nm}$ (cf. Figure 2a,c). The nanofiber morphologies of samples V75-SD and V95-SD were similar, so that the SEM image of V75-SD does not have to be shown here. The surface of sample V95-SD showed obvious roughness with some grooves (cf. Figure 2d), but the roughness was lower than that of sample V55-SD and higher than that of sample VRT-SD. In agreement with the roughness variation, the diameters of V75-SD and V95-SD were found to be between those of samples VRT-SD and V55-SD.
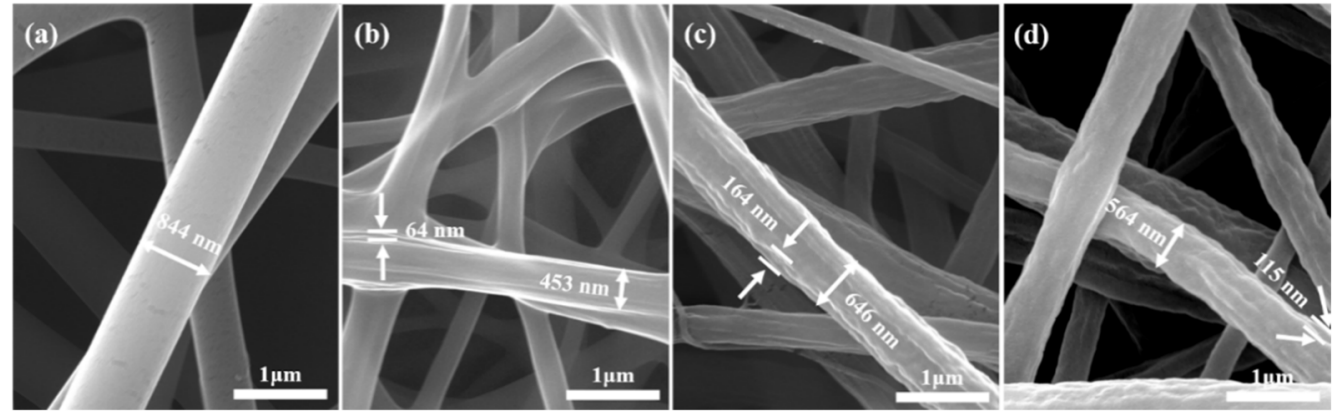

Figure 2. SEM photographs of samples (a) V, (b) VRT-SD, (c) V55-SD, and (d) V95-SD, with nanofiber diameters and surface-roughness values as indicated.

The two panels in Figure 3 show the element distributions in samples VRT and V55 obtained by means of EDX mapping. As expected, both samples contained Carbon, Oxygen, and Nitrogen. Vacuum drying at RT led to homogeneous distributions of $\mathrm{C}, \mathrm{O}$, and N on the nanofiber surfaces of sample VRT (top panel of Figure 3). Vacuum drying at the elevated temperature of $55^{\circ} \mathrm{C}$ yielded quite a different element distribution for sample V55. The bottom panel of Figure 3 reveals a homogeneous distribution of $\mathrm{C}$ and $\mathrm{O}$, but a heterogeneous distribution of $\mathrm{N}$ on the nanofiber surface of sample V55. The black regions enclosed by yellow ellipses near the nanofiber contours indicate a lack of Nitrogen and thus a nonuniform overall concentration of PVP. The concentration variation of the PVP resulted from the morphology variations between samples VRT and V55, as the surface roughness of V55 was achieved through the removal of the PVP in ethanol.
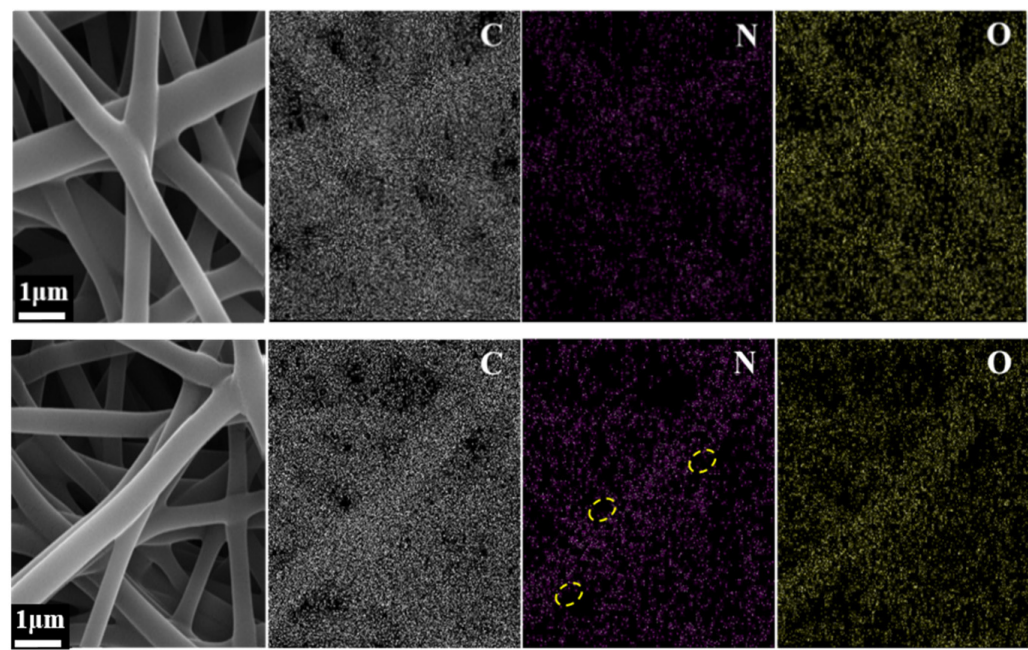

Figure 3. EDX element-distribution maps of samples VRT (top panel) and V55 (bottom panel). 


\section{Discussion}

The observations suggest a hypothesis (schematically shown in Figure 4) for the surface reconstruction during vacuum drying at either RT or elevated temperatures. The surface morphologies can be traced back to the electro-spinning process, in which electrostatic repulsion of surface charges deforms each PVA/PVP droplet into a Taylor cone. The charged jet ejected from the Taylor cone is stretched and split into new finer jets, so that water evaporates quickly and leaves PVA as the polymer to crystallize first, if the very high solubility of PVP in water is taken into account. On the other hand, PVP and the remaining water still exist as a concentrated solution inside the nanofibers, as evidenced from the high softness and stickiness of sample V. Therefore, the inner-liquid and outer-crystallizing process can be reasonably assumed to yield to nanofiber shells that are metastable, meshlike PVA layers [17]. The subsequent vacuum drying at RT allows the internal water in the fibers to carry PVP molecules uniformly from the inside to the outside through the PVA mesh-like layers. Capillary forces from the PVP/water migration and compression forces from the water evaporation can lead to significant cracking and shrinkage of the PVA meshlike layers. Thus, after the PVP removal by selective dissolution, a significant reduction of the nanofiber diameter and a slightly wrinkled nanofiber surface can be expected-as seen in the SEM image of sample VRT-SD in Figure $2 b$. In the case of vacuum drying at the elevated temperature of $55^{\circ} \mathrm{C}$, the mesh-like PVA layer is thermally softened. Therefore, the capillary force from water migration leads to deformation instead of cracking in the PVA mesh. The following water evaporation boosts the formation of this undulating profile on the PVA layer. As a result, after selective dissolution, the nanofiber has no obvious reduction in diameter but exhibits a significant increase in rough surfaces (cf. Figure 2c).

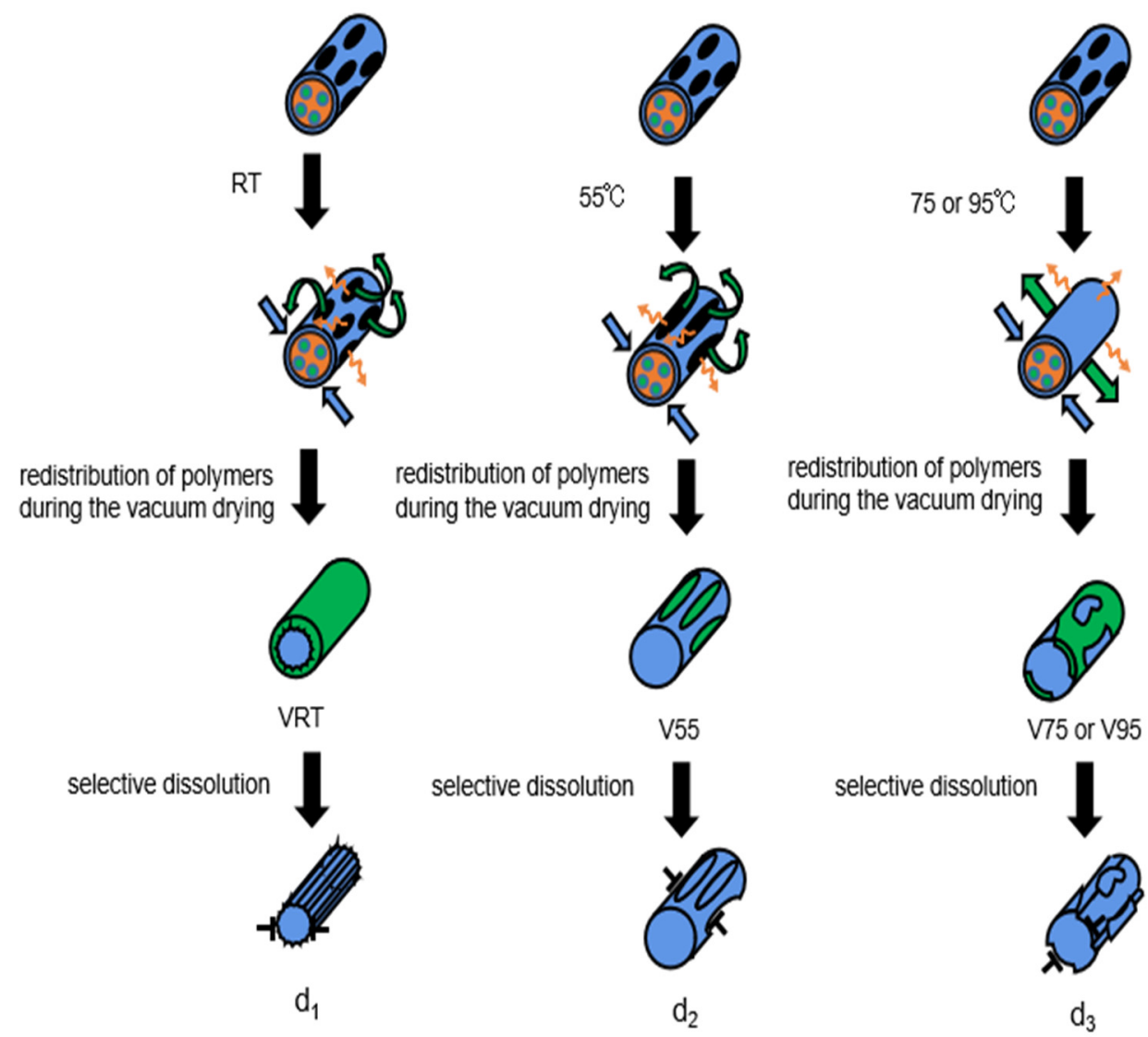

Figure 4. Surface reconstruction process during vacuum drying at various temperatures (Green, blue, orange, and black regions on the fiber represent PVP, PVA, water, and mesh voids, respectively. The green, blue, and orange arrows in the diagram represent the traveling directions of PVP, PVA, and water, respectively). 
As mentioned above, further elevated temperatures of 75 or $95{ }^{\circ} \mathrm{C}$ during vacuum drying of the V75-SD and V95-SD samples led to smaller morphology changes than in samples VRT-SD and V55-SD. Upon exposure to the two higher temperatures, PVA tends to be quickly dissolved in water together with PVP, which produces some PVA fragments. Hence, the capillary force is strongly reduced, but the compression force from the water evaporation generates an axial motion of PVA fragments, as indicated in Figure $2 d$, instead of a radial crash or deformation of the PVA mesh-like layer. This is supported by the SEM images in Figure 2d.

The water evaporation is evident from the results of Fourier-Transform Infrared (FTIR) and X-ray Photoelectron Spectroscopy (XPS) scans. In Figure 5, the FTIR peaks at 1660 and $1290 \mathrm{~cm}^{-1}$ are attributed to $\mathrm{C}=\mathrm{O}$ and $\mathrm{C}-\mathrm{N}$ bonds in ketone, respectively, and the broad peak at $3300 \mathrm{~cm}^{-1}$ indicates hydrogen bonds [18,19]. Taking sample V as a reference, the PVP content, quantifiable by the signature peak for $\mathrm{C}=\mathrm{O}$ bonds at $1660 \mathrm{~cm}^{-1}$, shows an increase, followed by a decrease and a second increase, i.e., changes to $197 \%, 31 \%, 51 \%$, and $74 \%$, respectively, for VRT, V55, V75, and V95.

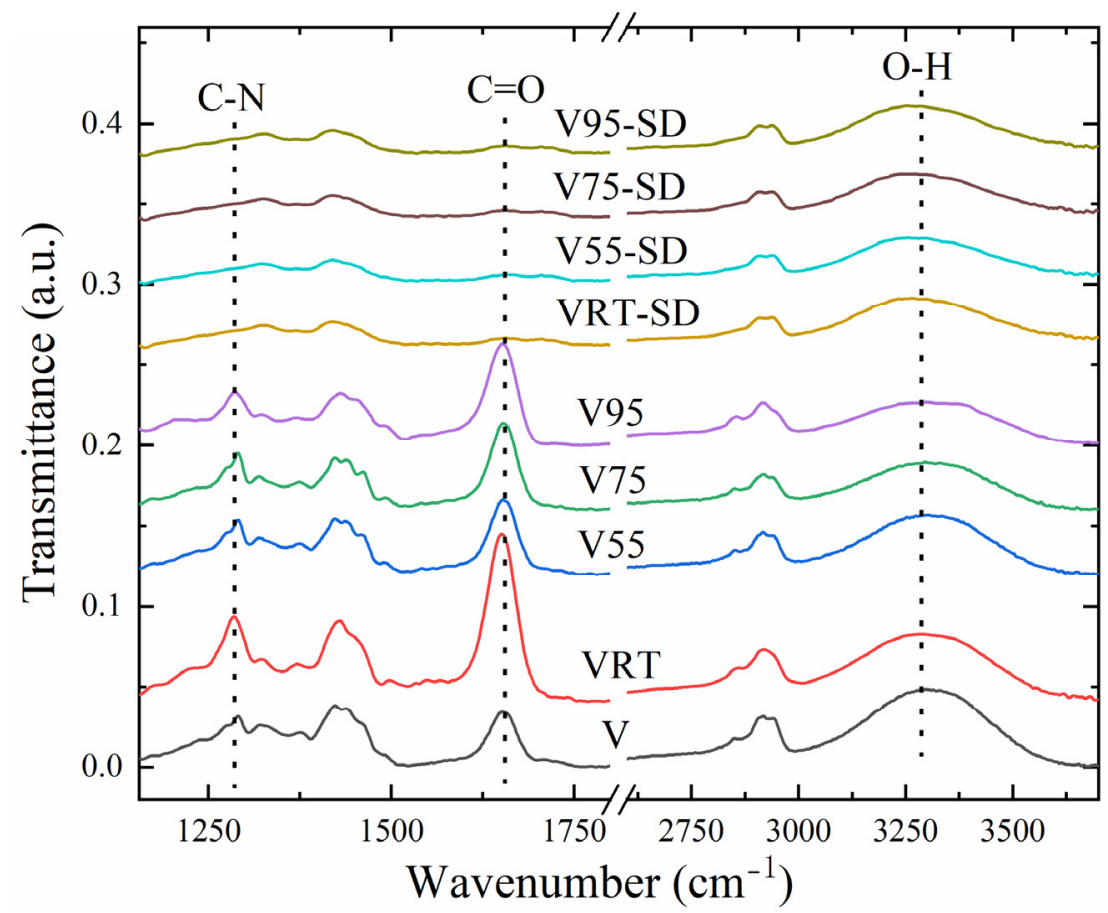

Figure 5. FTIR spectra of the nanofibers in all 9 differently prepared and treated samples.

Beside water, internal hydrogen bonds in both polymers also contributed to the FTIR peak at $\sim 3300 \mathrm{~cm}^{-1}$. We assume that the sample V95 represents only PVA, since there is no reason for water molecules to remain in the sample. The prominent $\mathrm{O}-\mathrm{H}$ peak at $\sim 3300 \mathrm{~cm}^{-1}$ indicates a considerable water content for sample V. When the vacuum-drying temperature increases from RT to $95{ }^{\circ} \mathrm{C}$, this leads to increasing water losses-as indicated by a strong reduction of the peak starting at $\sim 3100 \mathrm{~cm}^{-1}$ (cf. the FTIR curves for samples VRT, V55, V75, and V95).

The selective dissolution of the PVP rendered the FTIR spectra of samples VRT-SD, V55-SD, V75-SD, and V95-SD almost identical. As expected, the peaks for C-N $\left(1660 \mathrm{~cm}^{-1}\right)$ and $\mathrm{C}=\mathrm{O}\left(1290 \mathrm{~cm}^{-1}\right)$ are not visible, implying the absence of PVP because of the selective dissolution. We notice, however, that selective dissolution has slightly impaired the broad peak for hydrogen bonding at $3300 \mathrm{~cm}^{-1}$, which probably indicates a lower hydroxyl concentration due to the loss of PVP during selective dissolution.

XPS, a highly sensitive method for surface analysis with a typical probing depth of 5-10 nm, is highly feasible for investigating the near-surface composition in nanofibers. As indicated in Figure 6, the peaks at 285, 399, and $531 \mathrm{eV}$ represent the C1s, N1s, and O1s 
orbitals, respectively [20]. The high O content (32.22\%) in sample V confirms the existence of a PVA shell for the nanofibers because PVA features the highest intrinsic $\mathrm{O}$ content $(\sim 36 \%)$. Under the assumption that PVA and PVP were both uniformly distributed with a $50 / 50$ (wt./wt.) ratio, the atomic ratio of $\mathrm{N}$ is $6.43 \%$. In Figure 6, the atomic ratios of $\mathrm{N}$ for samples V, VRT, V55, V75, and V95 are found to be 3.14\%, 9.90\%, 3.66\%, 3.99\%, and 4.04\% respectively. The $\mathrm{N}$ content in V55, V75, and V95 is similar, but exhibited a slight increase with temperature, which means that $55^{\circ} \mathrm{C}$ is the critical vacuum-drying temperature to yield a uniform distribution of PVA and PVP on nanofiber surfaces. The slightly increased $\mathrm{N}$ content in samples V75 and V95 was due to a corresponding decrease of $\mathrm{O}$, because more bound water was eliminated at $75^{\circ} \mathrm{C}$ and $95^{\circ} \mathrm{C}$ compared to $55^{\circ} \mathrm{C}$. The results support the hypothesis that vacuum drying at RT leads to PVP-rich nanofiber surfaces, while vacuum drying at 55, 75, and $95^{\circ} \mathrm{C}$ yields the opposite result, i.e., a PVA-rich surface. It is obvious that the XPS results agree well with the FTIR observations. The XPS spectra indicate that more PVA was collected on the nanofiber surfaces of these samples (notice the O1s peak at $531 \mathrm{eV}$ increases sharply for sample V55, because each PVA molecule has a hydrogen bond, while PVP does not).

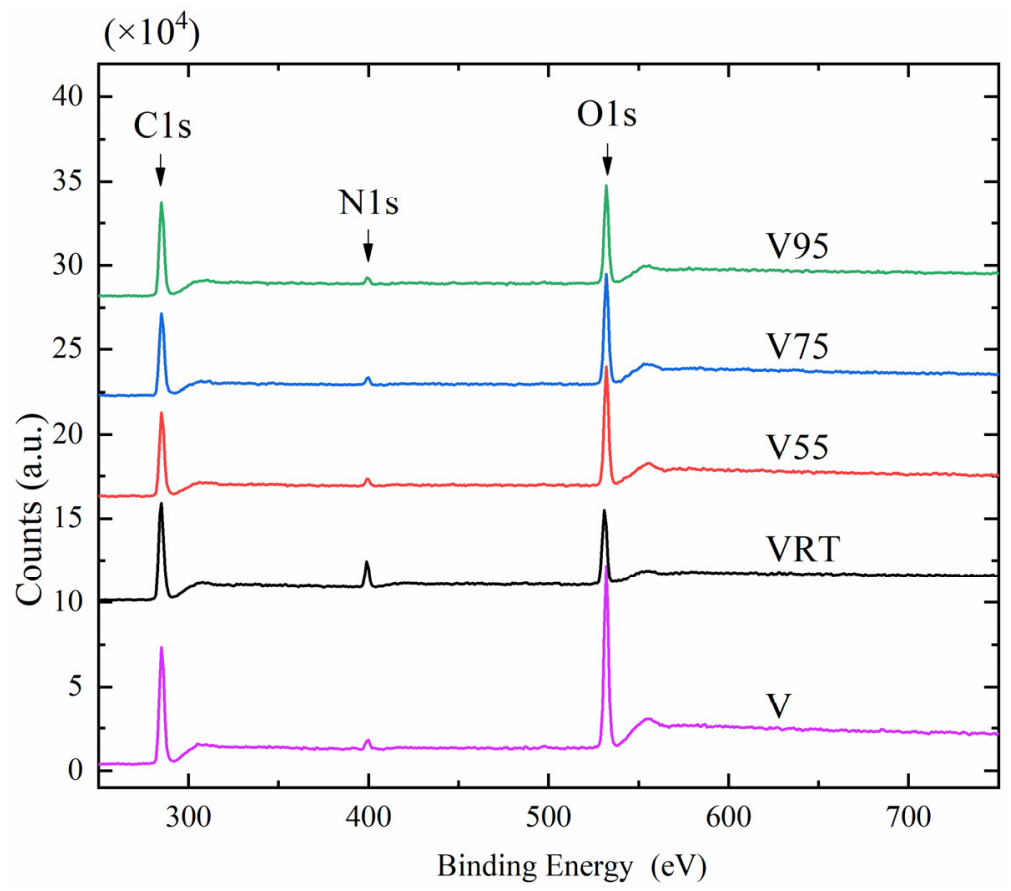

Figure 6. XPS spectra of nanofiber samples (Peaks of $\mathrm{C}, \mathrm{O}, \mathrm{N}$ are marked out).

\section{Conclusions}

In conclusion, reconstruction of PVA/PVP nanofiber surfaces can be achieved and controlled by water evaporation during vacuum drying at selected temperatures. The intermolecular forces induced by the water evaporation are recognized as the drivers of the process. It was found that vacuum drying at $55{ }^{\circ} \mathrm{C}$ equips the nanofibers with significant surface roughness due to the combined effects of the capillary forces from water migration and the compression forces from water evaporation, a process that has been proven to be a feasible route for obtaining a high roughness on PVA nanofibers and, thus, for enabling specific applications that require nanofibers with nano-structured surfaces.

Author Contributions: Conceptualization, F.W.; methodology, Z.Z.; validation, Y.Y. and Z.S.; formal analysis, F.W. and Z.Z.; investigation, Z.Z.; resources, F.W.; data curation, Q.W.; writing-original draft preparation, Z.Z.; writing-review and editing, F.W. and R.G.; visualization, F.W. and R.G.; supervision, F.W. All authors have read and agreed to the published version of the manuscript. 
Funding: The authors gratefully acknowledge financial support from the NSFC (92166206) and the 111 Project of the Ministry of Education of China (BP0820005).

Institutional Review Board Statement: Not applicable.

Informed Consent Statement: Not applicable.

Data Availability Statement: The data that support the findings of this study are available from the corresponding author upon reasonable request.

Acknowledgments: The authors gratefully acknowledge the equipment support (electron microscope, XPS equipment, etc.) from Analytical and Testing Center of Chongqing University.

Conflicts of Interest: The authors declare no conflict of interest. The funders had no role in the design of the study; in the collection, analyses, or interpretation of data; in the writing of the manuscript, or in the decision to publish the results.

\section{References}

1. Huang, L.; Manickam, S.S.; McCutcheon, J.R. Increasing strength of electrospun nanofiber membranes for water filtration using solvent vapor. J. Membr. Sci. 2013, 436, 213. [CrossRef]

2. Din, I.U.; Shaharun, M.S.; Naeem, A.; Alotaibi, M.A.; Alharthi, A.I.; Bakht, M.A.; Nasir, Q. Carbon nanofibers as potential materials for catalysts support, a mini-review on recent advances and future perspective. Ceram. Int. 2020, 46, 18466. [CrossRef]

3. Mane, P.P.; Ambekar, R.S.; Kandasubramanian, B. Electrospun nanofiber-based cancer sensors: A review. Int. J. Pharm. 2020, 583, 119364. [CrossRef] [PubMed]

4. $\quad$ Kalantari, K.; Afifi, A.M.; Jahangirian, H.; Webster, T.J. Biomedical applications of chitosan electrospun nanofibers as a green polymer-Review. Carbohydr. Polym. 2019, 207, 588. [CrossRef] [PubMed]

5. Xue, J.; Wu, T.; Dai, Y.; Xia, Y. Electrospinning and electrospun nanofibers: Methods, materials, and applications. Chem. Rev. 2019, 119, 5298. [CrossRef]

6. Al-Enizi, A.M.; Zagho, M.M.; Elzatahry, A.A. Polymer-based electrospun nanofibers for biomedical applications. Nanomaterials 2018, 8, 259. [CrossRef]

7. Jalaja, K.; Naskar, D.; Kundu, S.C.; James, N.R. Potential of electrospun core-shell structured gelatin-chitosan nanofibers for biomedical applications. Carbohydr. Polym. 2016, 136, 1098. [CrossRef] [PubMed]

8. Homaeigohar, S.; Davoudpour, Y.; Habibi, Y.; Elbahri, M. The electrospun ceramic hollow nanofibers. Nanomaterials 2017, 7, 383. [CrossRef] [PubMed]

9. Yang, Y.; Chang, S.; Bai, Y.; Du, Y.; Yu, D.-G. Electrospun triaxial nanofibers with middle blank cellulose acetate layers for accurate dual-stage drug release. Carbohydr. Polym. 2020, 243, 116477. [CrossRef] [PubMed]

10. Li, Z.; Xu, Y.; Fan, L.; Kang, W.; Cheng, B. Fabrication of polyvinylidene fluoride tree-like nanofiber via one-step electrospinning Mater. Des. 2016, 92, 95. [CrossRef]

11. Kim, G.-M.; Le, K.H.T.; Giannitelli, S.M.; Lee, Y.J.; Rainer, A.; Trombetta, M. Electrospinning of PCL/PVP blends for tissue engineering scaffolds. Mater. Sci. Mater. Med. 2013, 2, 1425. [CrossRef] [PubMed]

12. Han, T.; Ma, S.; Xu, X.; Xu, X.; Pei, S.; Tie, Y.; Cao, P.; Liu, W.; Wang, B.; Zhang, R. Rough SmFeO3 nanofibers as an optimization ethylene glycol gas sensor prepared by electrospinning. Mater. Lett. 2020, 268, 127575. [CrossRef]

13. Nguyen, T.N.; Moon, J.; Kim, J.J. Microstructure and mechanical properties of hardened cement paste including Nylon 66 nanofibers. Build. Mater. 2020, 232, 117134. [CrossRef]

14. Fong, H.; Chun, I.; Reneker, D.H. Beaded nanofibers formed during electrospinning. Polymer 1999, 40, 4585. [CrossRef]

15. Zhao, J.; Sun, Z.; Shao, Z.; Xu, L. Effect of surface-active agent on morphology and properties of electrospun PVA nanofibres. Fibers Polym. 2016, 17, 896. [CrossRef]

16. Wen, P.; Wen, Y.; Zong, M.H.; Linhardt, R.J.; Wu, H. Encapsulation of bioactive compound in electrospun fibers and its potential application. J. Agric. Food Chem. 2017, 65, 9161. [CrossRef]

17. Lim, M.; Kwon, H.; Kim, D.; Seo, J.; Han, H.; Khan, S.B. Highly-enhanced water resistant and oxygen barrier properties of cross-linked poly (vinyl alcohol) hybrid films for packaging applications. Prog. Org. Coat. 2015, 85, 68. [CrossRef]

18. Baganizi, D.R.; Nyairo, E.; Duncan, S.A.; Singh, S.R.; Dennis, V.A. Interleukin-10 conjugation to carboxylated PVP-coated silver nanoparticles for improved stability and therapeutic efficacy. Nanomaterials 2017, 7, 165. [CrossRef]

19. Deniz, A.E.; Vural, H.A.; Ortaç, B.; Uyar, T. Gold nanoparticle/polymer nanofibrous composites by laser ablation and electrospinning. Mater. Lett. 2011, 65, 2941. [CrossRef]

20. Okpalugo, T.; Papakonstantinou, P.; Murphy, H. High resolution XPS characterization of chemical functionalised MWCNTs and SWCNTs. Carbon 2005, 43, 153. [CrossRef] 